Mykola Sysyn - Vitalii Kovalchuk - Ulf Gerber - Olga Nabochenko - Bogdan Parneta*

\title{
LABORATORY EVALUATION OF RAILWAY BALLAST CONSOLIDATION BY THE NON-DESTRUCTIVE TESTING
}

The property of railway track to resist the irreversible deformation for a long-term operational loading considerably depends on the ballast layer. The ballast layer is the element of a railway track whose mechanical properties and state are formed in-situ with the help of the ballast cleaning, tamping and distributing machines. The varied properties of the ballast material to obtain the form during the maintenance and retain it during the operation are equally important for the ballast layer. The control over the processes of the ballast consolidation and deconsolidation by means of measurement methods could potentially provide great possibilities for improvement of its properties both during the maintenance and operation. The paper deals with an experimental study of the railway ballast consolidation and deconsolidation processes under the vibration loading of the sleeper. A non-destructive measurement method is proposed to investigate the distribution of the ballast consolidation along the sleeper. The method is based on the measurement of time of mechanical wave propagation. Modern low-cost sensors and powerful microcontroller techniques enable creating smart measurement systems for automatic multi-point data acquisition, online processing and statistical estimation of the ballast consolidation distribution.

Keywords: railway ballast, tamping, consolidation, wave propagation, seismic method, non-destructive measurement

\section{Introduction}

The operation of the railway track and its maintenance or construction depend considerably on the ballast layer. The ballast layer is an element of the track superstructure, where the residual deformations accumulate most quickly. The reason is that the ballast is a grained material that poorly absorbs the dynamic loads from the rolling stock. The occurrence of geometrical irregularities of the track, as a result of uneven settlements of the ballast layer, causes dynamic load on the track, which affects the work of all of its elements. Besides that, the ballast layer is an element of the track superstructure with the least industrialized degree of construction and maintenance. Unlike other elements, such as rails, sleepers, fastenings, the ballast layer formation occurs directly on the track during its construction. Thus, the property of the ballast material to easily change its shape during the construction and at the same time sustainably maintains a given shape throughout the lifecycle of the track are two contradictory requirements that are demanded of the ballast layer. The effect on these properties of the ballast is achieved during its consolidation. The control over this parameter and knowledge of its influence on the ballast deformation processes can allow to significantly optimize the track superstructure, as well as the work of the ballast tamping machines.

The quality control and the ballast layer influence on duration of the track lifetime are the subject of numerous studies and publications in recent years [1-6]. The investigations [7-8] have discovered a significant effect of the ballast layer consolidation and ballast filling on the construction of railroad engineering buildings. A simulation of railway track and turnout geometry deterioration due to inhomogeneous settlements of ballast layer is presented in [9-10].

Behavior of the ballast layer under the influence of a number of factors, including the initial stage of filling, the elasticity of the subgrade and the vibrational impact of the rolling stock have been studied in detail by the authors of [11-13]. Authors in [14] present theoretical analysis of the ballast vibration characteristics and their influence on a loose contact between the sleeper and ballast layer that causes a higher settlement of the ballast track.

The experimental determination of the quality of the ballast layer consolidation of the railway track is the basis of the authors' research [15-17]. A comprehensive review of the non-destructive methods of evaluation of the ballast layer consolidation is presented in [18].

The majority of methods of non-destructive evaluation of the ballast layer consolidation are based on measurements of the passage of elastic wave by geophones or accelerometers. The measurement of wave passage, analysis and determination of soil properties are the main tasks of a seismic survey. Application of the seismic survey methods for construction and transport purposes is based in SASW (Spectral Analysis Surface Waves) and MASW (Multichannel Analysis of Surface Waves) [1920]. Those methods are based on the kinematic and dynamic interpretation of impact response of surface waves. The advantage of those methods is the simple arrangement of measuring sensors on the surface of the soil; the disadvantage is the relatively low resolution ability in inhomogeneous soil properties determination.

The methods of the wave propagation analysis are inextricably linked with mathematical methods of information processing, signal analysis and statistics. The application of

\footnotetext{
* ${ }^{1}$ Mykola Sysyn, ${ }^{2}$ Vitalii Kovalchuk, ${ }^{1}$ Ulf Gerber, ${ }^{2}$ Olga Nabochenko, ${ }^{3}$ Bogdan Parneta

${ }^{1}$ Institute of Railway Systems and Public Transport, Technical University of Dresden, Germany

${ }^{2}$ Department of the rolling stock and track, Lviv branch of Dnipropetrovsk National University of Railway Transport, Lviv, Ukraine

${ }^{3}$ Department of Construction industry, Lviv Polytechnic National University, Lviv, Ukraine

E-mail: mykola.sysyn@tu-dresden.de
} 


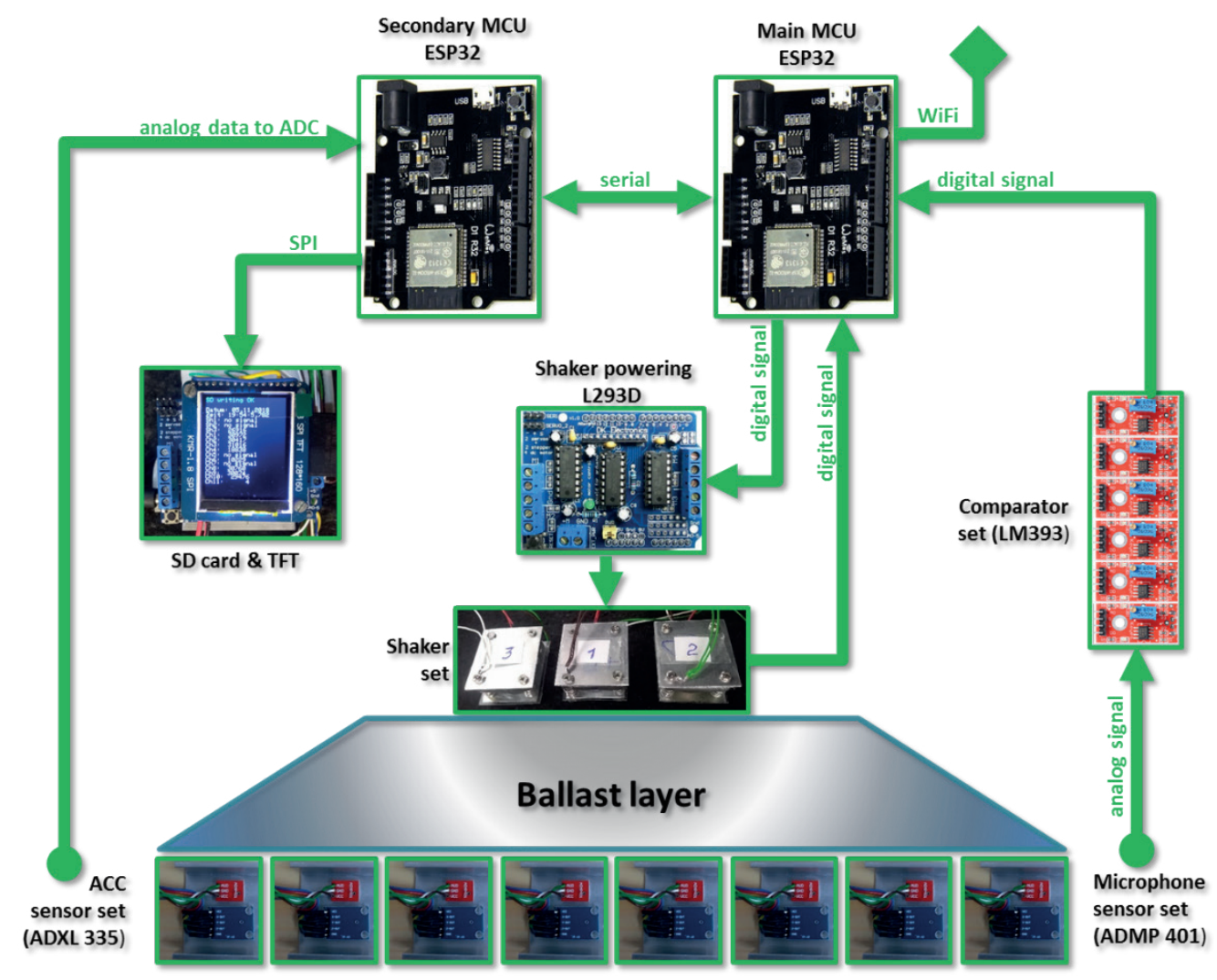

Figure 1 Structural scheme of the device for measurements of ballast layer consolidation

methods of machine and deep learning allow not only to automate the processing and interpretation of data, but also significantly increase the degree of information use and accuracy of measurements [21-22]. In the study [23] methods of cluster and discriminant analysis were used to identify the characteristic features of the ballast layer consolidation.

The purpose of this article is to develop the techniques for the laboratory determination of the ballast layer consolidation based on the non-destructive methods of geophysics. The method of measuring of the ballast layer consolidation should meet the following requirements:

- The measured value should vary depending on the ballast layer consolidation within considerable limits with regard to random fluctuations, providing sufficiently low relative error.

- The spatial separating ability of the ballast layer density measurement should not be less than a half of the thickness of the ballast layer; i.e. measurements must be performed simultaneously by a dense network of sensors.

- Dynamic and kinematic interpretation of the impulse response is based on the measurements of velocity of the wave propagation and acceleration.

- The measurement system should provide automatic measurements, data acquisition and their storing for the analysis.

Along with development of the method, it is necessary to determine the effect of the ballast layer consolidation on the measured velocity of the waves propagation and acceleration.

\section{Development of the method for laboratory determination of ballast layer consolidation}

The basis of the method for determining the ballast layer consolidation is measurement of velocity of the longitudinal waves passage through the ballast layer and recording of dynamic oscillations. The induction of dynamic oscillations and their registration are carried out by the developed device, the structural scheme of which is shown in Figure 1. The device consists of two programmable microcontrollers of type ESP-32, which control and create impulses, obtain digital signals and digitize analogue signals from sensors, pre-process, evaluate and store information with the output of current information about work fulfilment on the screen. Microcontrollers synchronously perform distributed tasks under direction of the main unit, which is synchronized with the Internet time. The elements of the periphery are three electromagnetic shakers that create a series of impacts in three points of the ballast layer. Shakers power management is performed by the program of the main microcontroller with digital control via Motor Shild L293D. MEMS sound microphones such as ADMP 401 (M1-M10) and ADXL 335 tri-axle accelerometers are used as sensors. The analogue information from the microphones about the time of wave propagation is digitized by the comparator system and transmitted digitally to the main controller. This method allows carrying out mass simultaneous measurements by the network up to 48 sensors per 1 microcontroller unit. The analogue information of acceleration signals of longitudinal and transverse waves from six accelerometers is digitized with the frequency of $15 \mathrm{kHz}$ and is stored on an SD card. 


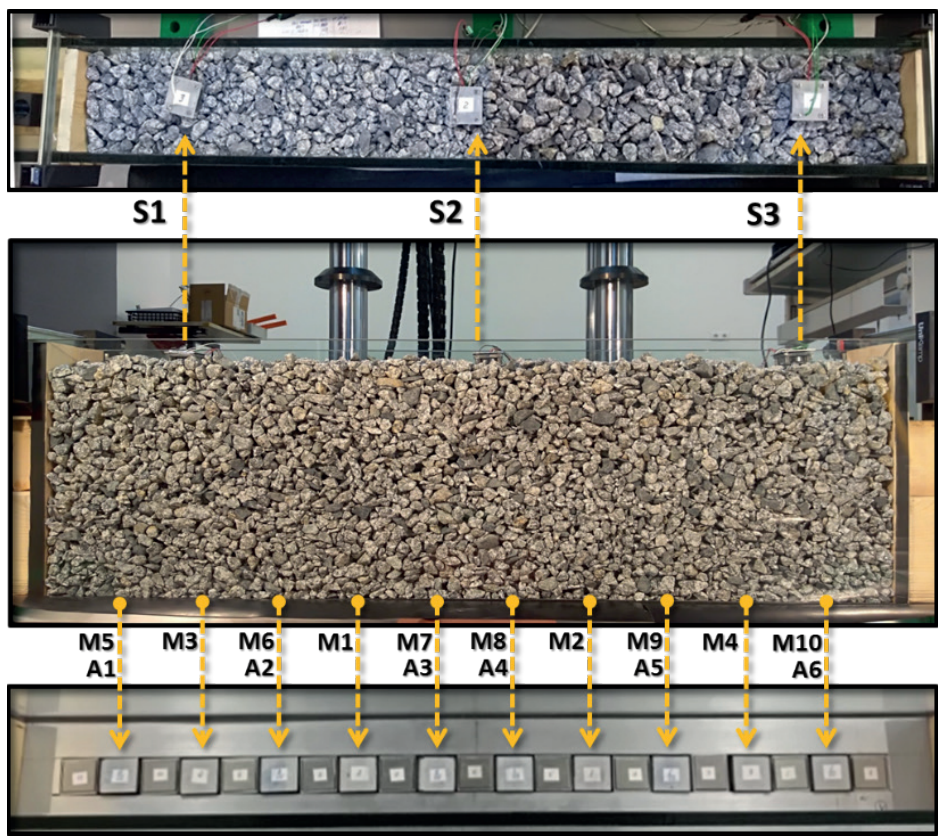

Figure 2 Sensors and shaker location in the ballast box (bottom: accelerometers (A1-A6) and microphones (M1-M10) under the ballast, top: location of shakers on the ballast surface, middle: view from the ballast side in the box with glass walls)

Before starting the measurement of the ballast layer consolidation, the microcontroller is synchronized with the real time through the server of the global Internet. After the synchronizing the microcontroller by means of the developed SeismoDens software, the programmed ESP-32 microcontroller launches Motor Shild, which controls the operation of shakers. The source of elastic waves from a shaker is an impact of an electromagnet on a metal plate with transverse dimensions of $5 \mathrm{~cm}$ by $3 \mathrm{~cm}$, which is placed on the ballast after each stage of the ballast consolidation. The shakers consist of housing and a built-in electromagnet, which is attracted to the bottom of the metal housing; it creates an impulse while being powered. Shakers impulses occur in turn with the start time of the impulse recorder by means of separate digital channels on the main microcontroller board. At first, the impact is given by the shaker number 1 (lefthand side of the ballast layer), followed by the shaker number 2 (ballast layer center) and shaker number 3 (right-hand side of the ballast layer) in Figure 2. Getting statistically reliable data on time of the waves propagation in a granular ballast environment is provided by the program of a microcontroller, which creates a series of impacts from each of the shakers in the amount of 12 times. After fixing the initial wave propagation moment, by means of MEMS microphones ADMP401, the momentum passage through the ballast layer is recorded.

In addition to microphones to perform dynamic interpretation of the ballast consolidation signals, the recording of vibration accelerations, since the moment of impact, has been done using acceleration sensors ADXL 335 (accelerometers in Figure 1 have numbers from A1 to A6). The width of the impact of the shakers is chosen so that the wavelength is greater than the distance between the transmitter of impact (shaker) and receiving sensors (microphones and accelerometers). This is a compulsory condition for correct determination of speed of the sound signal propagation. After each measurement, the sound and acceleration measurements are recorded into a file with the name according to the recording date and the operating time of the device.

The laboratory bench for studying the degree of ballast consolidation is the ballast box filled with crushed stone of the size $1.0 \times 0.17 \times 0.33 \mathrm{~m}$ (Figure 2). The side walls of the box are thick-walled glass slabs to monitor the movement of ballast particles and perform photogrammetric measurements. This box is filled with crushed stone of granite fractions $8 / 16$ to a depth of $0.27 \mathrm{~m}$ without consolidation. The end walls are capable to fulfil the longitudinal displacement when the ballast pressure reaches the friction resistance.

The bottom of the box consists of c-channel profiles where the signal cables and power supply to the sensors are placed. Sound sensors and accelerometers are placed in separate parts of the metal profile with the width and length of $40 \mathrm{~mm}$ and the height of $20 \mathrm{~mm}$. These elements are separated from adjacent sensors and the base by the noise-isolation material in order to partially exclude the side-effects from the hydro-pulse. The total number of separate profiles with sensors is 10 pcs. Six of them are with common location of ADXL335 acceleration sensors and ADMP 401 microphones and four profiles are only with microphones. Microphones in Figure 2 have symbols from M1 to M10, accelerometers have symbols from A1 to A6 and shakers have symbols from $\mathrm{S} 1$ to $\mathrm{S} 3$.

\section{Experimental studies of the ballast layer consolidation}

The laboratory studies consisted of a sequence of cycles of the ballast layer consolidation and impact response measurements. The load was carried out by a servo-hydraulic test machine ZWICK HB 160. The load was applied to an I-beam placed in the ballast box that occupied the entire perimeter of the ballast prism. 

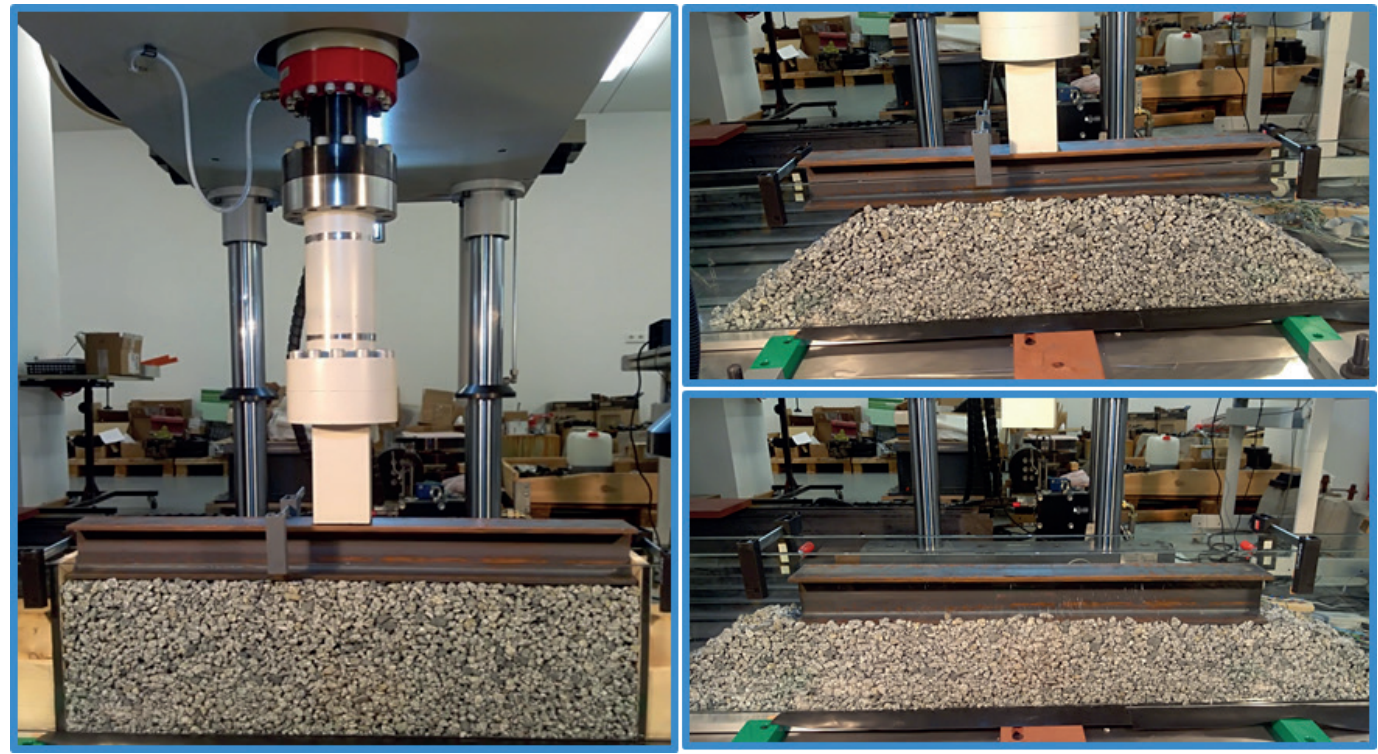

Figure 3 The ballast consolidation process in the laboratory experiment (left: initial state in cycle No1, right above: the ballast box without side enclosure after cycle No2, right below: the ballast settlement after cycle No2)
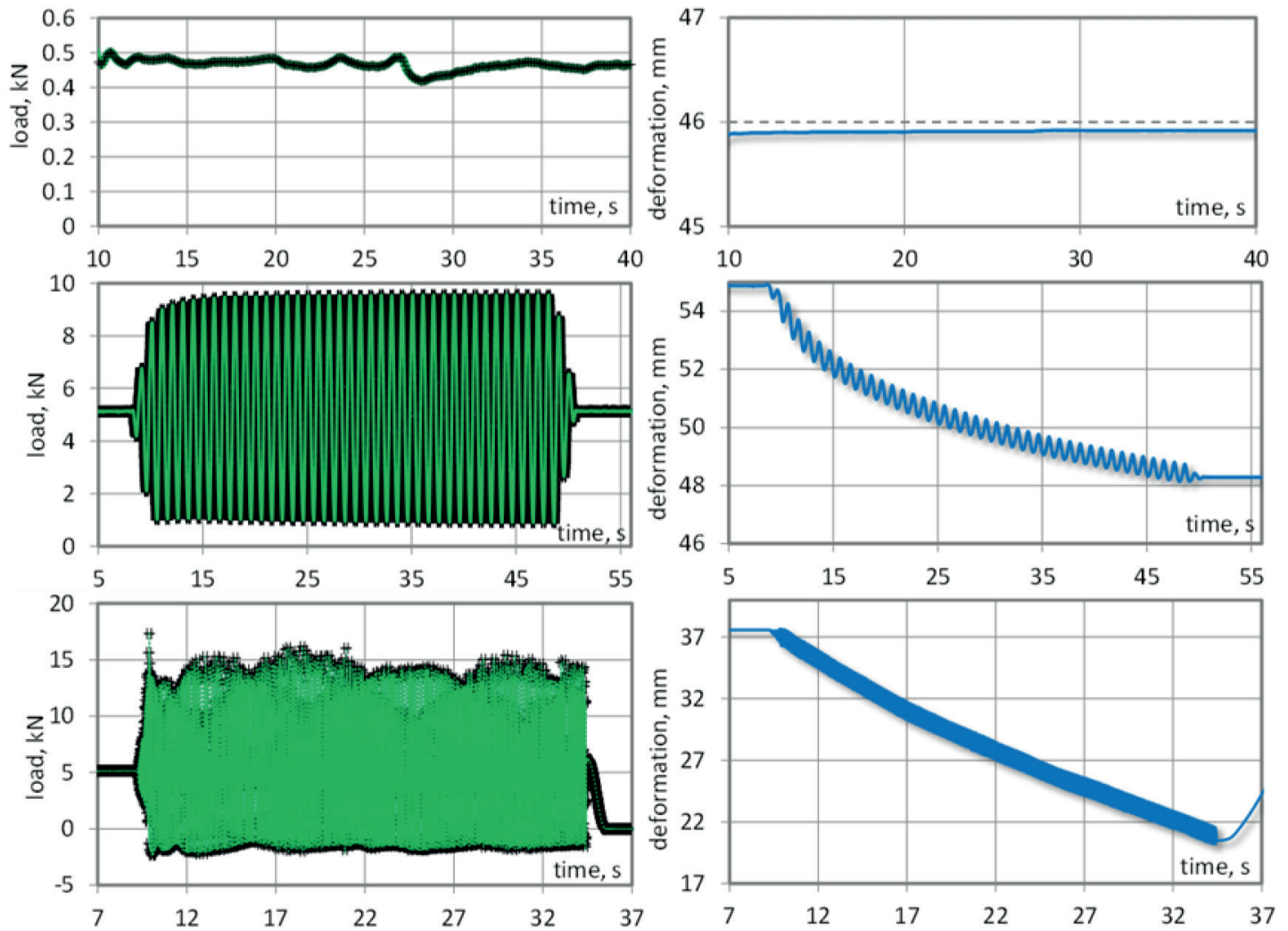

Figure 4 Load on the sleeper (on the left) and its settlement (on the right) in cycles No2 1 (above), No2 (in the middle) and No3 (bottom)

Figure 3 shows the ballast layer in 3 cycles of the experiment: before consolidation, intermediate state and after consolidation.

In each cycle of the experiment, static and dynamic loading were applied to the stamp, while the dynamic settlement of a sleeper was being measured. Dynamic loads and the results of a sleeper settlement in three cycles are shown in Figure 4. In the cycle No1, the constant loading through the stamp was $0.5 \mathrm{kN}$, while the residual settlement was almost not observed. During the cycle No2, a smooth change in loading from $0 \mathrm{kN}$ to $5 \mathrm{kN}$ was initially applied, and then the dynamic harmonic loading at a frequency of $1 \mathrm{~Hz}$, ranging from $0 \mathrm{kN}$ to $10.0 \mathrm{kN}$, was used. The overall stamp settlement is $6.7 \mathrm{~mm}$ in 25 load cycles. In the third cycle, the static load remained $5 \mathrm{kN}$ and the total dynamic load on the sleeper was $15 \mathrm{kN}$ with a frequency of $40 \mathrm{~Hz}$. At the same time the ballast was completely unloaded. The settlement was $19 \mathrm{~mm}$ per 1000 load cycles.

After each consolidation cycle, measurements of the elastic oscillation propagation in the ballast layer were made using the 


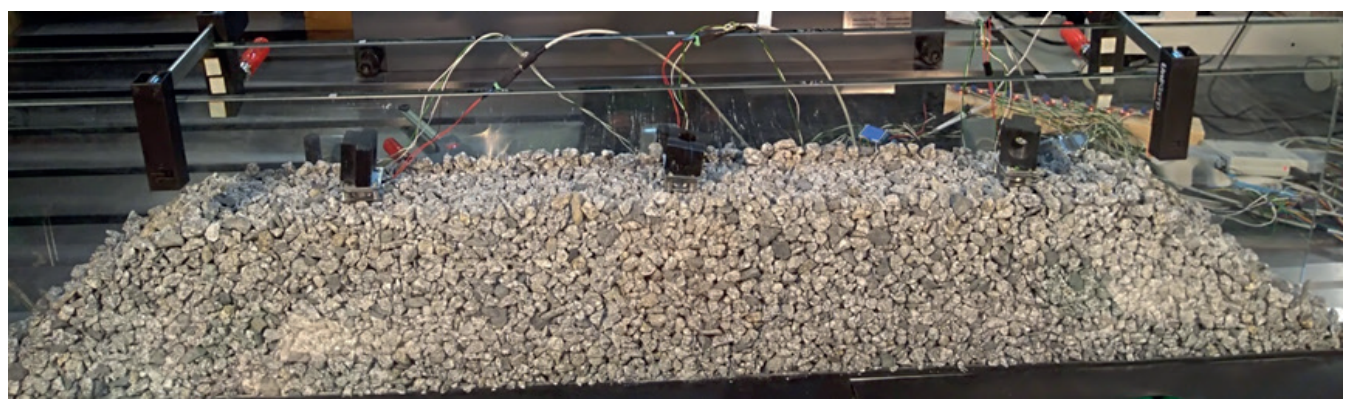

Figure 5 Measuring the ballast layer consolidation

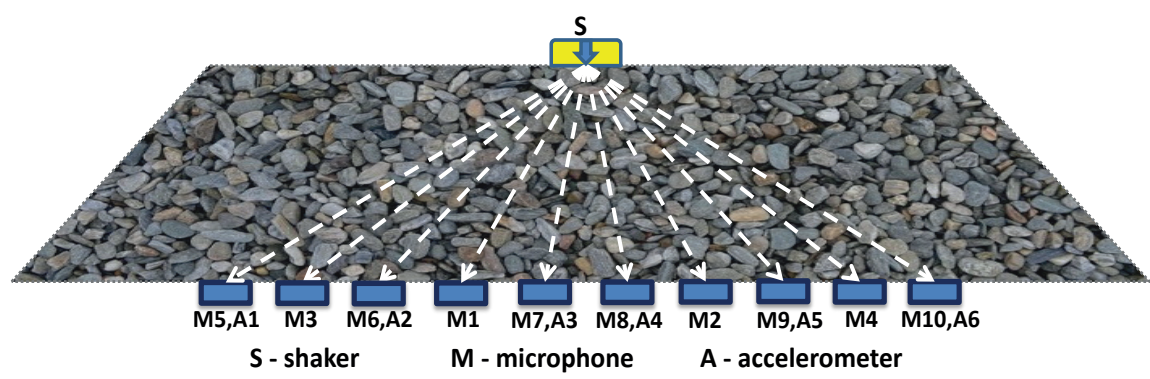

Figure 6 Measuring the ballast layer consolidation

developed method for determining the ballast layer consolidation. A group of shakers alternately created a series of 12 impacts, which were recorded and analysed by a series of ballast sensors of acceleration and sound distribution under the ballast. Figure 5 shows the process of measuring the ballast layer consolidation after the cycle No2 of the consolidation program with removed sleeper.

\section{Analysis of influence of the ballast layer consolidation on the propagation of elastic waves in the ballast layer}

The analysis of time and speed of waves propagation is carried out at three ballast consolidation states, namely: unconsolidated ballast, an intermediate state of the ballast consolidation and a ballast layer with maximum density of consolidation. The passage of elastic waves through a granular environment, which is the ballast layer of the railway, is determined according to the material and granulometric composition of the grains and, to a large extent, the number of contacts between grains, that is, the density of the ballast layer. Thus, measuring the velocity of elastic waves propagation after the shaker impact initiation, one can conclude about the degree of the ballast layer consolidation. The speed is determined by the known formula:

$V=\frac{L}{t}$,

where $L$ - path of a wave propagation from a shaker to a microphone; $t$ - time of wave passage from the impact (of a shaker) transmitter to the impact receiver (microphone).

The distance $L$ is determined depending on the thickness of the ballast layer after each consolidation cycle and the relative position of the shaker and sensors. Figure 6 shows the scheme of $L$ paths determination.
Then, the analysis of the impact of the ballast consolidation on the time and velocity of wave propagation in the case of shaker placing in the center of the ballast prism is carried out. The passage time of waves propagation from shaker No2 to sensors M3, M1, M2 and M4 at different consolidation cycles are shown in Figure 7. The passage time of a wave ranges from 1000 to 1500 $\mu$ for an unconsolidated state of the ballast and from 90 to 850 $\mu$ for maximum densities of the ballast. There is a significant increase in the passage time of a wave to side sensors, especially in the consolidated state. For sensors M1 and M2, which are the closest to the source of impacts, in the unconsolidated ballast, the average passage time of the wave through the granular medium is $1131 \mu$ s. For intermediate ballast compaction the average time is $737 \mu \mathrm{s}$, and for the maximum density of the ballast (according to experimental consolidation) the average propagation time of a wave is $298 \mu \mathrm{s}$. Consequently, the increase in the passage time of a wave through the ballast to a sensor in the ratio of propagation time of a wave in unconsolidated ballast to maximum density of the ballast is 3.7 times. Therefore, with increasing ballast consolidation, the passage time of a wave decreases. So, according to the time of the wave impact propagation from the source of impact to the receiving sensor, the degree of railway ballast consolidation can be assessed. The increase of time of the wave passage to side sensors is caused by the greater distance of the wave path.

To verify the method of determining the wave propagation time according to microphones records, the comparison of them to results of longitudinal waves records of accelerometers is performed. Figure 8 shows the records of longitudinal waves acceleration made by accelerometer A4 from shaker No2 after three cycles of consolidation, as well as the moment of impact start. The average propagation time of the pressure wave, determined by the accelerometer, is numbered after cycles No1, 2, 3 , respectively, $1850 \mu \mathrm{s}, 830 \mu \mathrm{s}$ and $250 \mu$ s. Those results, taking into account the location of the accelerometer and the statistical 


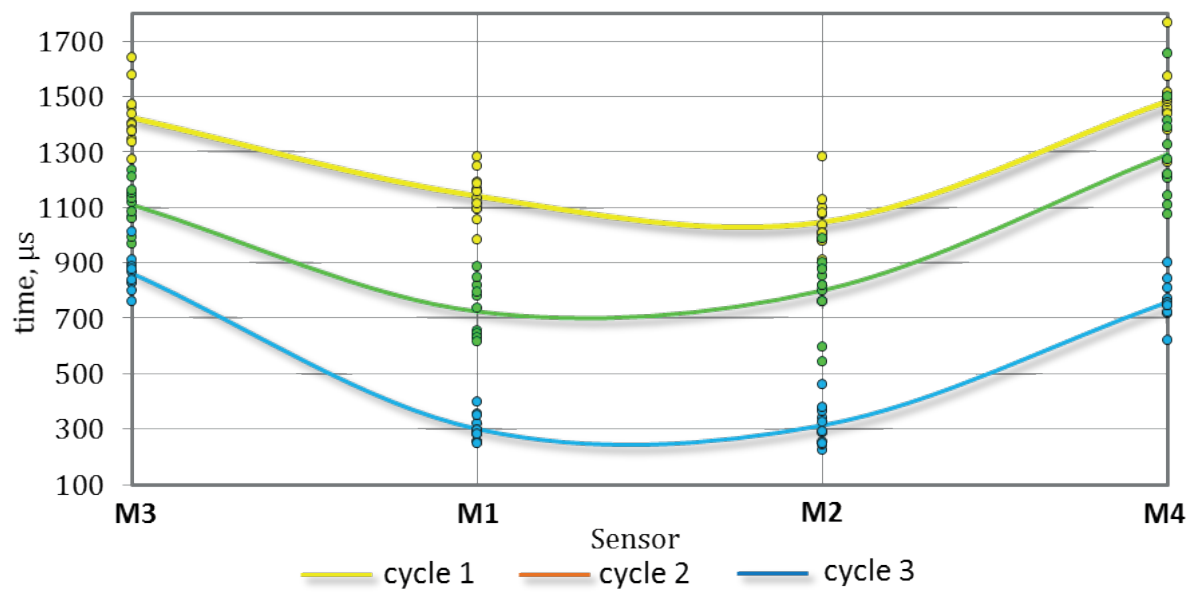

Figure 7 Time of pressure waves propagation with the given impact from a shaker No2

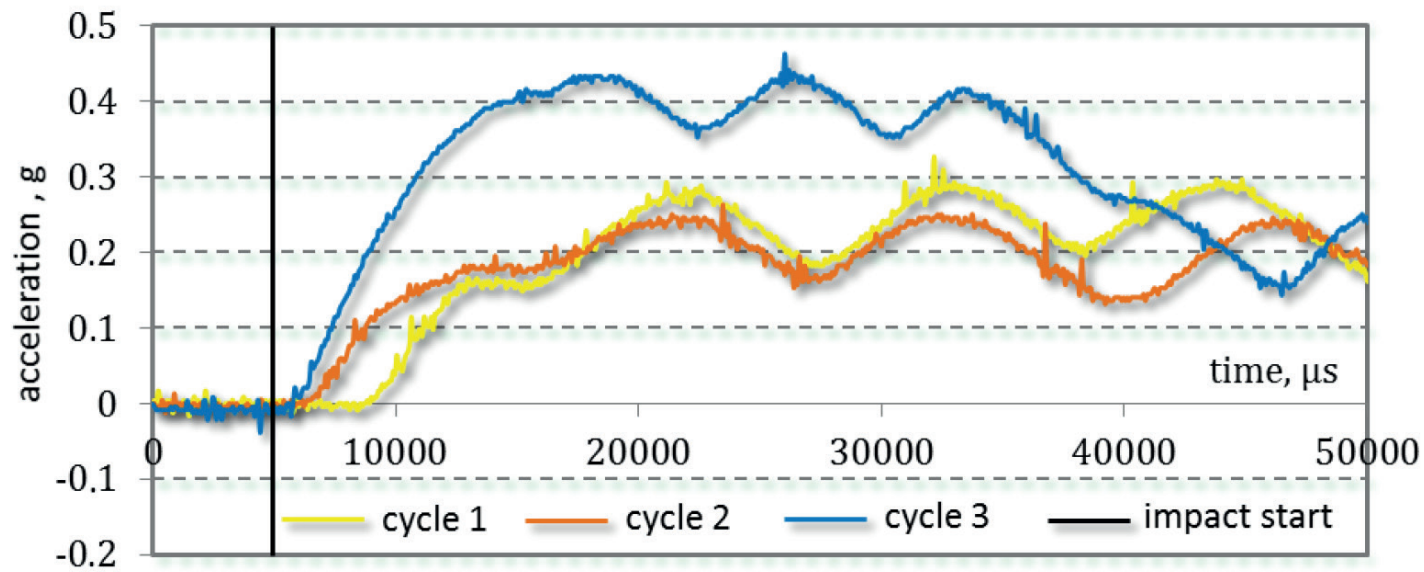

Figure 8 Records of longitudinal waves acceleration by accelerometer A4 from shaker No2

Table 1 Wave propagation velocities for different compaction states

\begin{tabular}{cllll}
\hline Ballast compaction & \multicolumn{3}{c}{ Velocity, m/s } & M4 \\
\cline { 2 - 5 } & M3 & M1 & M2 & 263 \\
low & 274 & 260 & 284 & 289 \\
intermediate & 333 & 377 & 344 & 440 \\
high & 386 & 732 & 717 & \\
\hline
\end{tabular}

spread, are fully consistent with measurements due to the sound propagation. However, the advantage of the microphone system is much greater accuracy of time measurement at high level of consolidation. In this case, according to the records of the wave passage time made by the accelerometer with the frequency of $13300 \mathrm{~Hz}$ at the highest density, the wave passage numbers 12 levels of a digitized signal. Accuracy increase can be achieved by the frequency increase, which inevitably leads to a proportional reduction of accelerometers in number and that is a disadvantage of this method of measurement. Thus, the proposed method of multisensory simultaneous measurement by microphones is a promising alternative to traditional methods.

The velocity of sound propagation according to times in Figure 7 is shown in Figure 9. In the case of impact setting from the central shaker No2 with unconsolidated ballast, an average wave propagation velocity to M1 microphone is $260 \mathrm{~m} / \mathrm{s}$, with an intermediate ballast compaction is $377 \mathrm{~m} / \mathrm{s}$ and with the maximum compaction of the ballast is $732 \mathrm{~m} / \mathrm{s}$. An average wave propagation velocity to microphone M2 is $284 \mathrm{~m} / \mathrm{s}$, with an intermediate ballast compaction is $344 \mathrm{~m} / \mathrm{s}$ and with the maximum compaction of the ballast is $717 \mathrm{~m} / \mathrm{s}$.

The velocity of wave propagation to remote microphones M3 and M4 is $274 \mathrm{~m} / \mathrm{s}$ and $263 \mathrm{~m} / \mathrm{s}$, respectively, with unconsolidated ballast; with an intermediate ballast compaction is $333 \mathrm{~m} / \mathrm{s}$ and $289 \mathrm{~m} / \mathrm{s}$, respectively and with the maximum compaction of the ballast is $386 \mathrm{~m} / \mathrm{s}$ and $440 \mathrm{~m} / \mathrm{s}$, respectively. Results of measurement correspond to the values range from reference books [24] for sediment rocks. Results of determining the wave propagation velocities for three different compaction states are shown in Table 1.

The peculiarity of velocity distribution in Figure 9, in contrast to time distribution in Figure 8, is its almost the same indices at the initial stage. It is explained by the isotropy of ballast properties and homogeneity at all points of the ballast box. At the same 


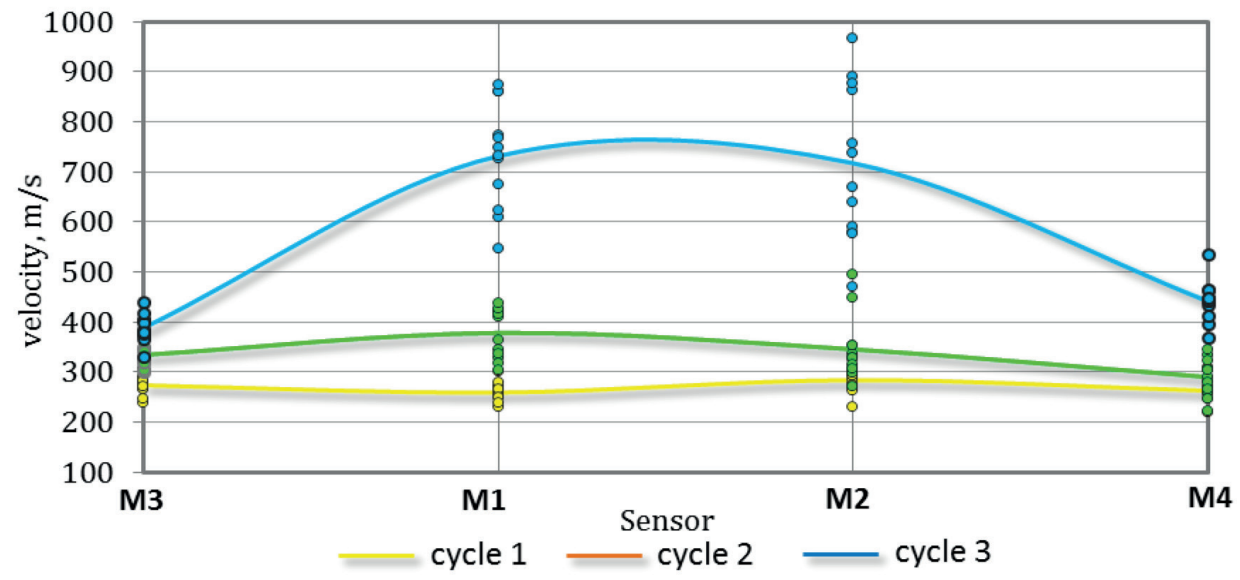

Figure 9 Speed of impact waves passage at different stages of the ballast layer consolidation and impulse assignment from shaker No2

time, it is necessary to underline the high level of measured speeds variations, which grows along with an average speed. Obtaining reliable values of velocity and consolidation of the ballast layer requires the use of modern statistical methods of data processing. Application of the newest powerful programmable microcontroller systems allows to automate statistical processing to online evaluation of the quality of measurements and the need for additional measurements.

\section{Summary and subsequent studies}

The ballast layer consolidation method has been developed and applied. It revealed a significant change in properties of the ballast during its deformation under the sleeper. The study proved the possibility of using the multi-sensory measurement by sound sensors in the field of wave front propagation instead of a complex method based on accelerometers. Results of measurements showed a significant local increase in the velocity of the longitudinal waves passage in the ballast layer. These results are confirmed by many studies that show the presence of consolidation zones under the sleeper.

The proposed approach will significantly improve the accuracy of determination of the ballast layer spatial consolidation during the tamping machines work, as well as in the process of modelling the operational deformations of the track. A promising area for further research is the application of computer statistics and machine learning algorithms for establishing interrelations between the ballast consolidation and characteristics of the impact response. Application of the modern sensor and microcontroller technologies allows simple and effective implementation of theoretical methods in creation of autonomous systems for monitoring the technical state of the track and engineering structures with the ballast layer.

\section{References}

[1] IZVOLT, L., HARUSINEC, J., SMALO, M. Optimisation of transition areas between ballastless track and ballasted track in the area of the tunnel Turecky vrch. Communications - Scientific Letters of the University of Zilina [online]. 2018, 20(3), p. 67-76. ISSN 1335-4205/eISSN 2585-7878. Available from: http://komunikacie.uniza.sk/index.php/communications/article/view/256

[2] WANG, H., MARKINE, V. Modelling of the long-term behaviour of transition zones: prediction of track settlement. Engineering Structures [online]. 2018, 156, p. 294-304. ISSN 0141-0296/eISSN 0141-0296. Available from: https://doi.org/10.1016/j. engstruct.2017.11.038

[3] FISCHER, S. Breakage test of railway ballast materials with new laboratory method. Periodica Polytechnica Civil Engineering [online]. 2017, 61(4), p. 794-802. ISSN 0553-6626/eISSN 1587-3773. Available from: https://doi.org/10.3311/PPci.8549

[4] FISCHER, S., JUHASZ, E. Railroad ballast particle breakage with unique laboratory test method. Acta Technica Jaurinensis [online]. 2019, 12(1), 26-54. eISSN 2064-5228. Available from: https://doi.org/10.14513/actatechjaur.v12.n1.489

[5] PLASEK, O., et al. Influence of under sleeper pads on track quality. Akustika. 2015, 23(1), p. 28-33. ISSN 1801-9064.

[6] NAGY, R. Description of rail track geometry deterioration process in Hungarian rail lines no. 1 and no. 140. Pollack Periodica [online]. 2017, 12(3), p. 141-156. ISSN 1788-1994/eISSN 1788-3911. Available from: https://doi.org/10.1556/606.2017.12.3.13

[7] KOVALCHUK, V., et al. Estimation of carrying capacity of metallic corrugated structures of the type multiplate mp 150 during interaction with backfill soil. Eastern-European Journal of Enterprise Technologies [online]. 2018, 1/1(91), p. 18-26. ISSN 1729-3774/ eISSN 1729-4061. Available from: https://doi.org/10.15587/1729-4061.2018.123002

[8] IZVOLT, L., SESTAKOVA, J., SMALO, M. Analysis of results of monitoring and prediction of quality development of ballasted and ballastless track superstructure and its transition areas. Communications - Scientific Letters of the University of Zilina. 2016, 18(4), p. 19-29. ISSN 1335-4205/eISSN 2585-7878. Available from: http://komunikacie.uniza.sk/index.php/communications/ article/view/284 
[9] NABOCHENKO, O., et al. Studying the railroad track geometry deterioration as a result of an uneven subsidence of the ballast layer. Eastern-European Journal of Enterprise Technologies [online]. 2019, 1/7(97), p. 50-59. ISSN 1729-3774/eISSN 1729-4061. Available from: https://doi.org/10.15587/1729-4061.2019.154864

[10] SYSYN, M., et al. Modelling and vehicle based measurements of ballast settlements under the common crossing. European Transport [online]. 2019, 71, p. 1-19. ISSN 1825-3997. Available from: http://www.istiee.org/te/

[11] GERBER, U., FENGLER, W. Setzungsverhalten des Schotters / Settlement behaviour of ballast (in German). Eisenbahntechnische Rundschau. 2010, 59(4), p. 170-175. ISSN 0013-2845.

[12] SYSYN, M., et al. The complex phenomenological model for prediction of inhomogeneous deformations of railway ballast layer after tamping works. Archives of Transport [online]. 2018, 47(3), p. 91-107. ISSN 0866-9546/eISSN 2300-8830. Available from: https://doi.org/10.5604/01.3001.0012.6512

[13] HOLTZENDORFF, K. Untersuchung des Setzungsverhaltens von Bahnschotter und der Hohllagenentwicklung auf Schotterfahrbahnen. /Investigation of the settlement behavior of railway ballast and voids development on ballasted tracks (in German). Ph.D. thesis, TU Berlin. 2013.

[14] WANG, B., MARTIN, U., RAPP, S. Vibration characteristic analysis of ballast with different aspect ratios by means of the discrete element method. In: WALUBITA, L. F., HOLLERAN, I., MWANZA, A. D. (eds.): Geo-China 2016: Resilient Railroad Materials and Structures to Mitigate Climate Change. Geotechnical Special Publication (268 GSP), 2016, p. 16-23. eISBN 9780784480113.

[15] SMUTNY, J., NOHAL, V. Vibration analysis in the gravel ballast by measuring stone method. Akustika. 2016, 25(1), p. 22-28. ISSN 1801-9064.

[16] SADEGHI, J. Field investigation on dynamics of railway track pre-stressed concrete sleepers. Advances in Structural Engineering [online]. 2010, 13(1), p. 139-151. ISSN 1369-4332/eISSN 2048-4011. Available from: https://doi.org/10.1260/1369-4332.13.1.139

[17] LAM, H., WONG, M. Railway ballast diagnose through impact hammer test. Procedia Engineering - The Twelfth East Asia-Pacific Conference on Structural Engineering and Construction : proceedings [online]. Vol 14. Elsevier, 2011. ISSN 1877-7058, p. 185194. Available from: https://doi.org/10.1016/j.proeng.2011.07.022

[18] BOLD, R. D. Non-destructive evaluation of railway trackbed ballast. PhD Thesis, Institute for Infrastructure and Environment, School of Engineering, University of Edinburgh, 2011.

[19] PARK, C. B., MILLER, R. D., RYDEN, N. Roadside seismic survey utilizing traffic noise. NDE Conference on Civil Engineering : proceedings. St. Louis, MO, USA, 2006, p. 323-334.

[20] SUSSMANN, T. R., et al. Use of seismic surface wave testing to assess track substructure condition. Construction and Building Materials [online]. 2017, 155, p. 1250-1255. ISSN 0950-0618/eISSN 1879-0526. Available from: https://doi.org/10.1016/j. conbuildmat.2017.02.077

[21] SYSYN, M., et al. Turnout monitoring with vehicle based inertial measurements of operational trains: a machine learning approach. Communications - Scientific Letters of the University of Zilina [online]. 2019, 21(1), p. 42-48. ISSN 1335-4205/eISSN 2585-7878. Available from: http://komunikacie.uniza.sk/index.php/communications/article/view/1166

[22] SYSYN, M., KOVALCHUK, V., JIANG, D. Performance study of the inertial monitoring method for railway turnouts. International Journal of Rail Transportation [online]. 2019, 7(2), p. 103-116. ISSN 2324-8378/eISSN 2324-8386. Available from: https://doi.org /10.1080/23248378.2018.1514282

[23] SYSYN, M., et al. Evaluation of railway ballast layer consolidation after maintenance works. Acta Polytechnica [online]. 2019, 58(6), p. 1-16, 2019. ISSN 1210-2709/eISSN 1805-2363. Available from: https://doi.org/10.14311/AP.2019.59.0077

[24] DAHM, T. Grundlagen der Geophysik / Basics of Geophysics (in German). Lecture Notes [online]. Potsdam: Deutsches GeoForschungs Zentrum GFZ, 2005. Available from: https://doi.org/10.2312/GFZ.2.1.2015.001 